\title{
THE NORTHEAST
}

a.sitis

WATER SUPPIY

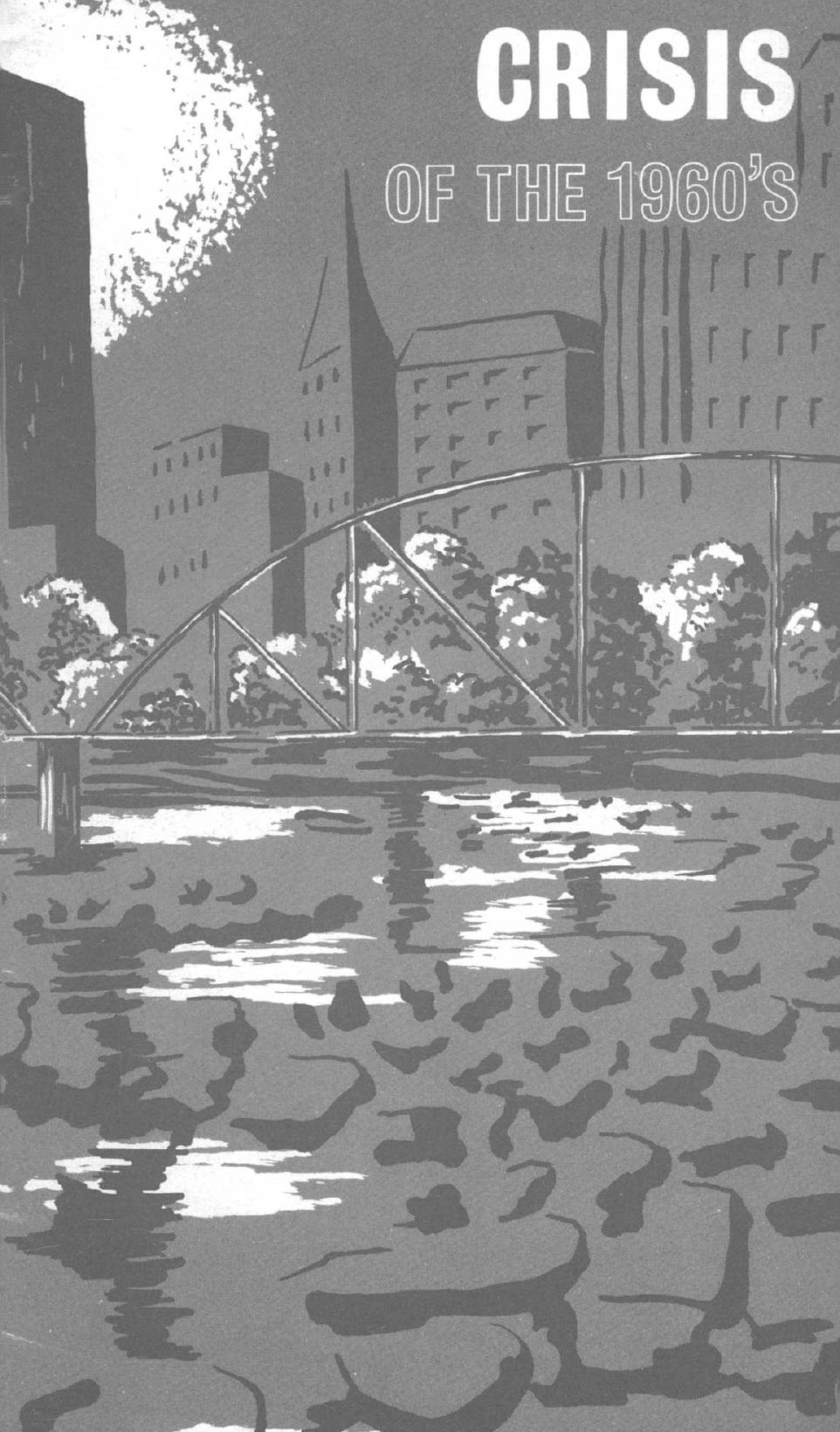

20 UNITED STATES DOEPARTMENIEOF THE INTERIOR GEOLOGICAL SURVEY 


\section{THE NORTHEAST}

WaATER SUPDLY

\section{CRISIS}

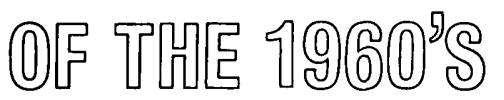

Drought is many things to many people. Essentially it is a dryness. Webster defines it as "a shortage of rain or of water." It is difficult to define a drought simply as a hydrologic or meteorologic phenomenon because in so many aspects it may also be a cultural phenomenon.

A water supply drought is a condition in which the developed water supply is temporarily inadequate for the many demands made on it by farms, cities, or industries.

The water supply drought in the Northeast began in the autumn of 1961 and marked the beginning of a severe water shortage that continued with little relief through the summer of 1966. During this time, throughout much of the Northeast, water supplies remained below normal.

The unusually long and severe water shortages in the Northeast during the 1960's emphasized the fact that drought is a national problem, and is not limited to any single geographic region or climate. Cities and industries, as well as farms, forests, and rural communities, need protection against long dry periods. 


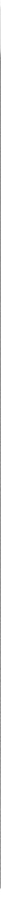

The Southwest region of the United States has already learned to make use, and re-use, of a meager water supply.

The five year water supply drought affected an area extending from New England to Virginia and from the Atlantic Coast to Ohio. The water supplies of millions of people were affected. Emergency measures were necessary to increase water supplies and to conserve water throughout the region.

The effects of the Northeast water supply drought on urban areas were especially notable during 1965 in northern New Jersey, New York City, and Philadelphia, where water demand is heavy and the supply is usually ample. In many ways these effects were similar to those of droughts that occur from time to time in the arid Southwest. 


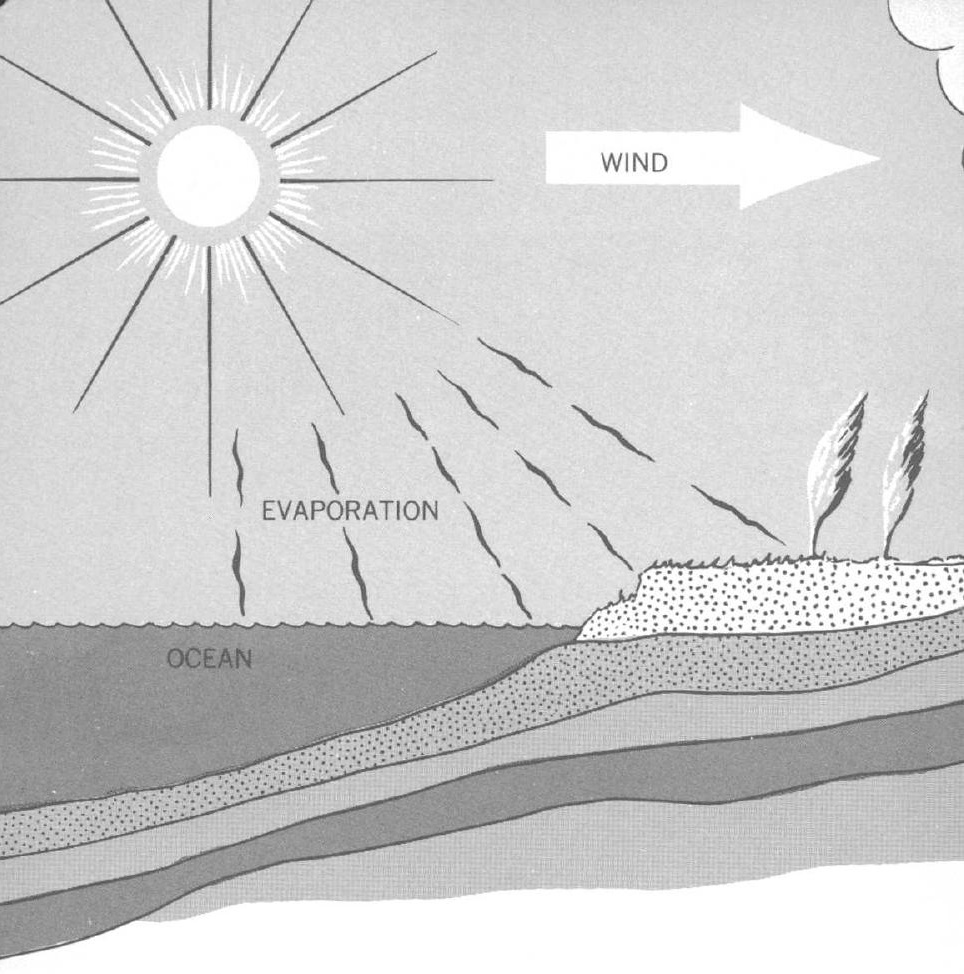

Water shortages in the Northeast were the result of the interaction of three factors: (1) The Northeast experienced an unusually long period of below-average precipitation; (2) The region's emergency reserves of water supply proved insufficient for the prolonged demands made on them; and (3) Pollution reduced the ability of many streams to provide a suitable water supply.

Although precipitation is necessary to replenish water supplies, the actual amount of precipitation within a short period is less significant than the supply available during that period to meet a region's heavy water demand. New York City alone has a demand of 1,250 million gallons per day during the summer months.

Water management facilities for providing emergency water supply in many areas were geared to the shorter dry spells that were typ- 


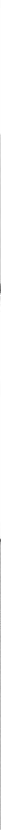

ical of the Northeast. Four years of subnormal precipitation depleted these reserves so that in 1965 many reservoirs were at one-third capacity or less.

Manmade structures, such as dams and reservoirs, are not the only means of storing and regulating reserve water supply. Nature itself stores water in rivers, lakes, ice and snow cover, soil moisture, and most of all, as ground water in aquifers (subsurface water-bearing rocks). The Northeast drought lasted so long that these natural sources of reserve water supply were seriously reduced. As the levels of ground water and streamflow declined the concentration of wastes increased, creating an additional pollution hazard.

The Northeast needed an extended period of plentiful rain or snowfall to end its water shortages and to restore the natural sources of water supply to their pre-drought levels. It wasn't until the summer of 1967 that these levels were again observed. 


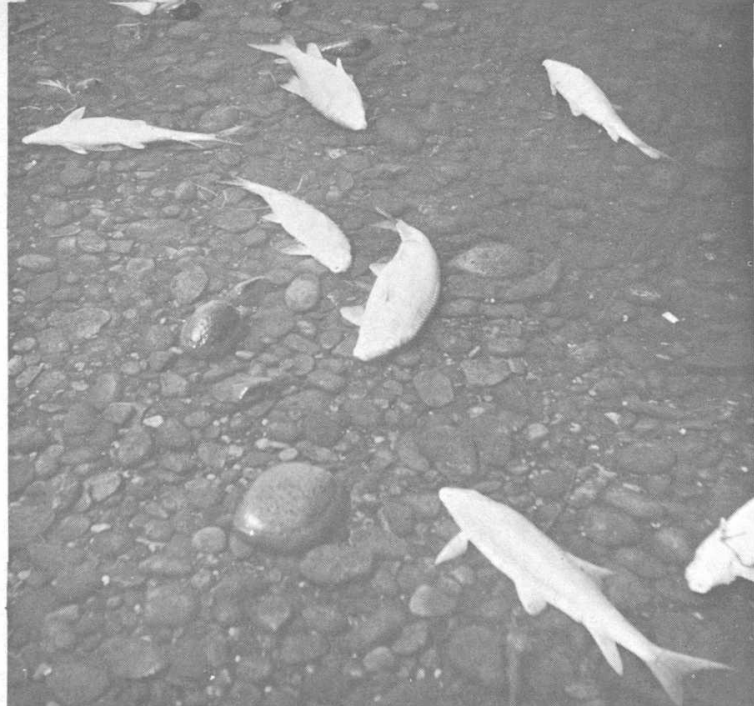

Photograph by Johnny Nicklas, Chief Photographer, Pennslyvania Fish Commission

The chronology of the effects of the Northeast drought on water supplies from 1961 to 1966 can be best illustrated by the mounting effects in the Delaware River basin where water shortages became increasingly serious each year. From the beginning of the drought in September 1961 until the end of 1962, the Delaware River basin had received less than 75 percent of its normal precipitation. In the next 4 years the cumulative deficiency totaled 40 inches, equivalent to the loss of an entire year's rain and snowfall.

Water shortages began to affect the Delaware River basin in 1962, about 6 months after the period of below-average precipitation began. Precipitation during the early spring of 1962 was nearly normal, but agricultural drought developed in the Delaware River basin as the available moisture was used but was not replenished by new rainfall. By midsummer, as precipitation fell below normal, soil moisture was depleted; some towns restricted the use of water for lawns and gardens, and some wells fell to record low levels.

By September 1963, 2 years after the dry period began, the rivers, lakes, reservoirs, and other surface sources of water supply through- 
out the Northeast were seriously affected as demands exceeded replenishment. Groundwater levels were also extremely low. By October, hundreds of domestic wells had gone dry and water use was restricted in numerous communities. The flow of the Delaware River in October 1963, for example, was the lowest for any October during the 50 years that records had been maintained by the Geological Survey.

The depletion of natural surface and underground sources of reserve water supply was a danger signal that intensified water shortages would follow without adequate replenishment. Heavy rainfall in late 1963 , restored some moisture to the soil, but the water levels in rivers, lakes, reservoirs, and ground-water sources remained subnormal.

The water supply drought continued in 1964 . Although rainfall was heavy in January and November it was only about half of normal throughout the growing season. The drought's effects spread to urban areas, with increasing competition for water by farms, cities, and industries.

As the water supply drought continued throughout 1965, water shortages became increasingly severe in New Jersey, southeastern New York, Massachusetts, and New Hampshire. Residents of New York City were required to make adjustments in their daily lives because of the scarcity of water. During the summer, air conditioning in New York City commercial establishments was limited, swimming pools and ornamental fountains were shut down, and citizens were urged to limit water use in their homes. Automobile washing and lawn sprinkling were prohibited. Some industries and commercial establishments in the Northeast curtailed operations; a few were forced to close down temporarily. 


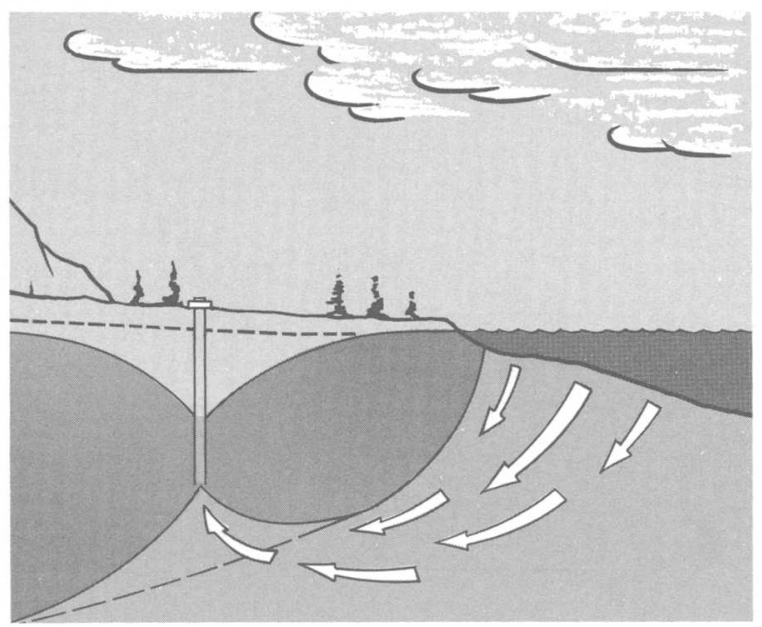

Salt water intrusion

Also, the water supply drought was damaging the quality of the Northeast's water. Some sources that might have been used in the emergency had already been made useless by pollution. Streamflow of the Delaware River during 1965 was inadequate to dilute the wastes of the area, and concentrations of chemical and organic pollutants increased. Tidal action mixed salt water from the ocean with the rivers, threatening fresh water supplies. Wells along the Atlantic Coast were contaminated by sea water that seeped into them after large amounts of fresh ground water were withdrawn. As the drought continued, pollution seemed likely to increase throughout the Northeast.

The water supply drought of the 1960's was probably the most severe the Northeast has experienced during historical times. Somewhat similar periods of low precipitation occurred during 1879-83 and 1892-96, but they did not produce equally severe effects upon the water supplies of the area. A much larger population with heavier water demands had to be served with the reduced water supply of the 1960's. 
In 1965, the Northeast relieved its water shortages to some extent by conservation and better management of its existing water supplies. A start was made to control the unnecessary uses of water. Large economies were attained by citizens voluntarily limiting their use of water. To many city dwellers in the Northeast came an awareness of the value of abundant clean water.

Administrators and scientists, both within and outside the Federal government, mobilized in a massive effort to relieve the immediate water shortages in the Northeast and to construct a broad water policy for the region. This regional cooperation may prove to be a model for like programs in other parts of the United States.

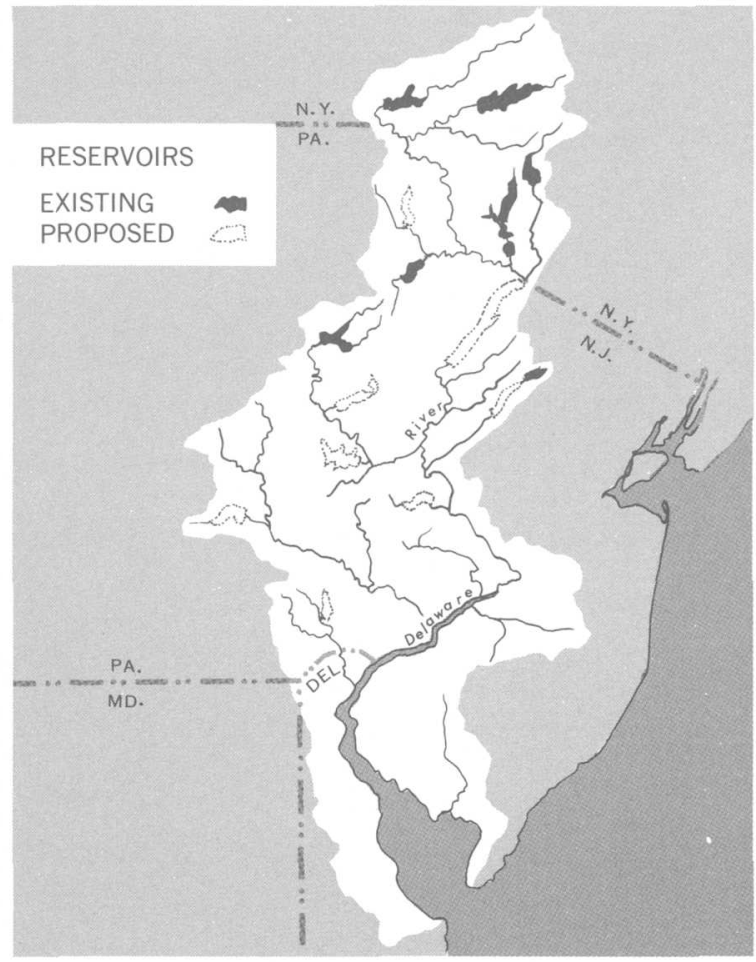

Water shortages may be alleviated by carefully planned basinwide facilities for managing the water of a river basin 
Several Federal agencies participated in an attack on the Northeast's water problems including the Department of Agriculture, U.S. Army Corps of Engineers, Public Health Service, the Federal Water Pollution Control Administration, Fish and Wildlife Service, Federal Power Commission, and the U.S. Geological Survey. The newly established Federal Water Resources Council was given its first opportunity to function in August 1965 when it assumed responsibility for coordinating all the Federal activities and resources being used to meet the Northeast's water problems.

Upon the recommendation of the Water Resources Council, the U.S. Geological Survey was assigned the task of coordinating an inventory of sources of emergency water supplies in the critical drought areas of the Northeast. This inventory included streams, reservoirs, and ground-water sources that might be used for supplementary water supply. In the most critical drought areas emergency sources of supply were identified and many were placed in use by local agencies.

Fortunately, normal to above-normal rainfall over key basins of the Northeast in

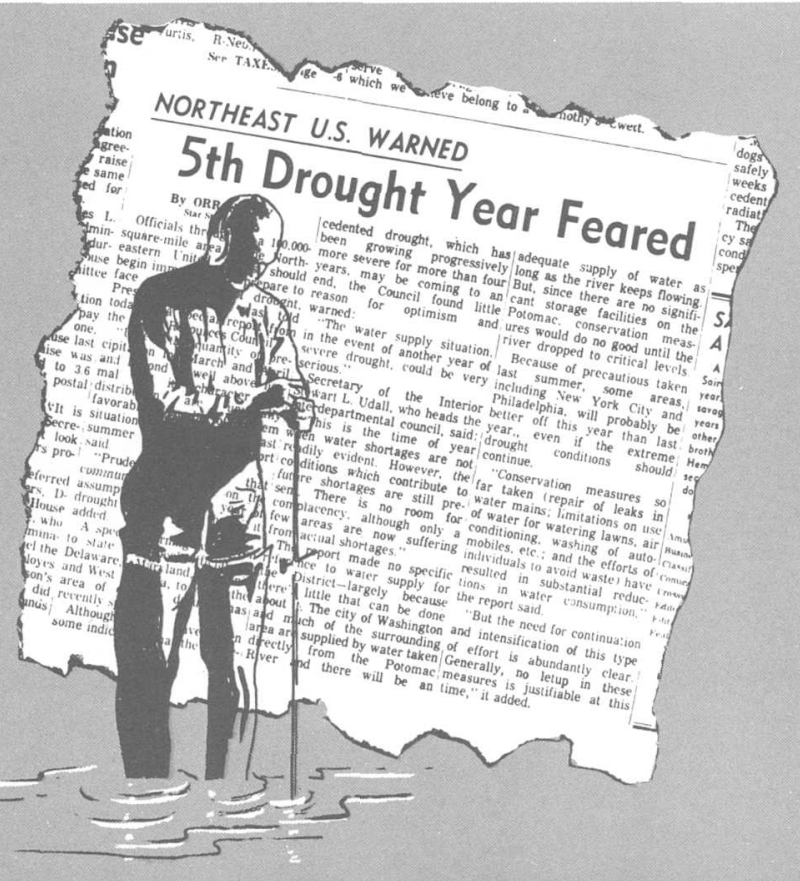




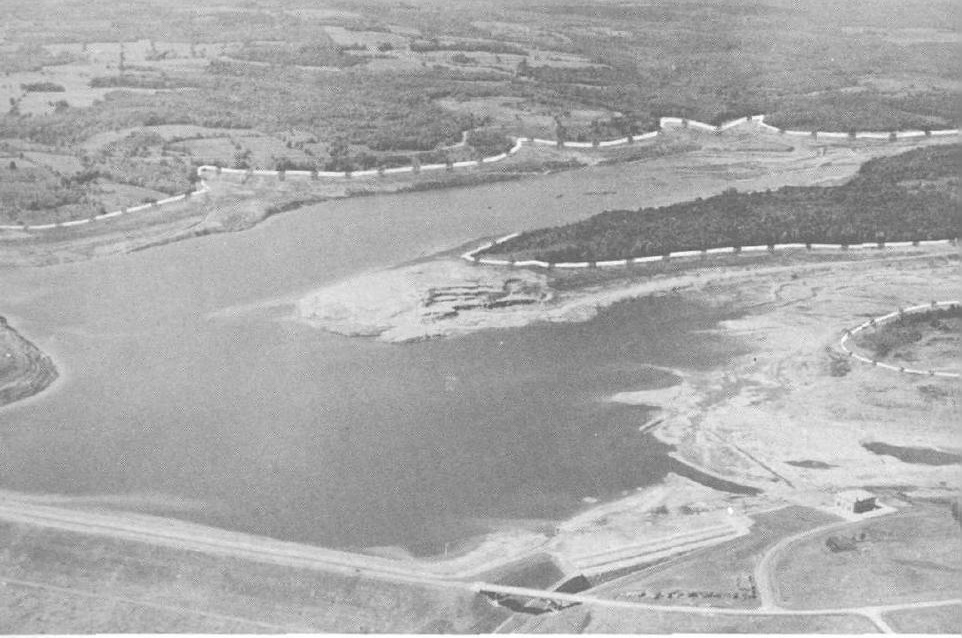

Reservoir storage at low ebb--dashed line shows level when full

September 1966 replenished water supplies in varying degrees in many critical or near-critical areas. However, the rains merely served to emphasize the fact that Nature seldom conforms to the wishes of man, as the drought was in fact succeeded by flooding in some localities. Soil moisture generally was replenished, and throughout much of the Northeast an increase in both streamflow and ground water was a welcome sign that marked at least a temporary lessening of the water shortages which had plagued the area.

The critical water shortages in the Northeast were a forecast of hardships that may arise in the future if adequate provision for drought is not maintained. A future prolonged dry period in the Northeast, or in any other part of the United States, could have more serious impact on a population significantly larger than it is today. With ever-increasing demands upon available supplies, the results could be catastrophic.

The cost of protection against water supply drought is high, both in human ingenuity and in financial investment. It will be necessary for citizens to decide what efforts they will make and what price they will pay to reduce their vulnerability to drought and assure themselves of ample clean water in the future. 


\section{FACTS ABOUT THE NORTHEAST WATER SUPPLY CRISIS AND ITS EFFECTS.}

AREA AFFECTED: All or part of 14 northeastern States; about 200,000 square miles equal to 7 percent of the conterminous United States. Areas most severely affected extended from eastern Massachusetts to eastern Pennsylvania, including New York City, northern New Jersey, and Long Island.

POPULATION OF AREA: About 50,000,000 persons, equal to 28 percent of the population of the United States, were affected. At least $20,000,000$ people were directly affected.

DURATION OF DROUGHT: September 1961 to September 1966. Times of greatest severity were July to October of each year, 1962 to 1966 , but especially 1965 and 1966 . Impact greatest during the growing season, when vegetation absorbs most of the precipitation, and water supplies rely heavily on storage.

\section{EFFECTS OF WATER SHORTAGE:}

On Water Supplies: Capacity of developed supplies severely taxed in many places although undeveloped resources far exceeded the need. Reservoirs, both surface and underground, were drawn down progressively year after year. Numerous rural and domestic wells failed. In 1965 , about one in eight public water supplies applied restrictions on water use. Also in 1965, the water supplies of New York City, Philadelphia, northern New Jersey, and of many smaller isolated communities had serious problems. In 1966, Washington, D. C., felt the threat of reduced supply.

On Water Quality: Flow of streams was too low to dilute and flush out wastes which resulted in serious pollution problems in many 
places. Major ground-water supplies not affected. Low flows in streams permitted salt water from the ocean to advance up the Delaware River almost to Philadelphia's water intake. There was similar encroachment in the James River and other tidal estuaries.

On Agriculture: Hay and other farm crops were far below average production. Dairy farms were hard hit as pasturelands became parched. Cranberry crops in Massachusetts were severely affected.

On Industry: Some industries dependent on public supplies reduced output and employment. On Recreation: Camping and hunting restricted because of fire hazards. Swimming, boating, and fishing in natural water reduced because of inadequate dilution of wastes. Many public swimming pools closed.

On Countryside: Dead and dying grass, trees, bushes and flowers detracted from the beauty of the countryside and showed the effects of the prolonged water shortage.

FIRE HAZARDS: Not enough water was available from many public water supplies to fight fires.

FOREST FIRES: Forest fires in Maine and New Jersey in 1963 approached record size and intensity. Fires in other parts of afflicted area were less serious.

RECURRENCE PROBABILITY: On the average, water shortages of this length and severity will recur in the Northeast only once in 200 years or more. This does not mean that it could not recur in 10 years, nor does this mean that it will necessarily recur in 200 years. 
Except for a few highly isolated and localized pockets, reservoirs, streams and ground-water levels in the Northeast have returned to normal, and now resemble the water-supply situation that existed before 1961. From a water standpoint, the back of the Northeast water supply crisis was broken in the spring of 1967 and it ended that summer.

The water-supply deficiencies taught many hydrologic lessons, and triggered several positive action programs as safeguards for the future. Cooperation among Federal, State and local officials resulted in better inventories of surfaceand ground-water supplies; spurred legal and political action or plans aimed at improvement of the development and management of water resources; and, in general, brought about an awareness that water-supply problems are not necessarily just water problems; rather they are frequently people problems, requiring the cooperative efforts of physical scientists, engineers, social scientists, administrators, managers and, of course, every citizen.

The 1961-66 Northeast water-supply problem was a test, in a way, for all who have water resource responsibilities, from those who must gather and disseminate data, to those who are responsible for development and management, and for control of pollution. Much was learned from the experience, yet, we would be seriously remiss if we failed to recognize the need for vigilance-for further studies and "action" planning to minimize the impact of future water shortages.

18 August 1967

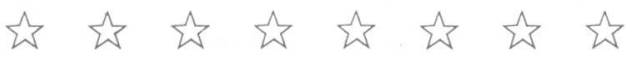

From material provided by Henry C. Barksdale. 


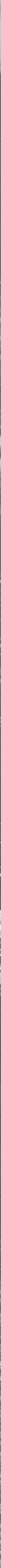




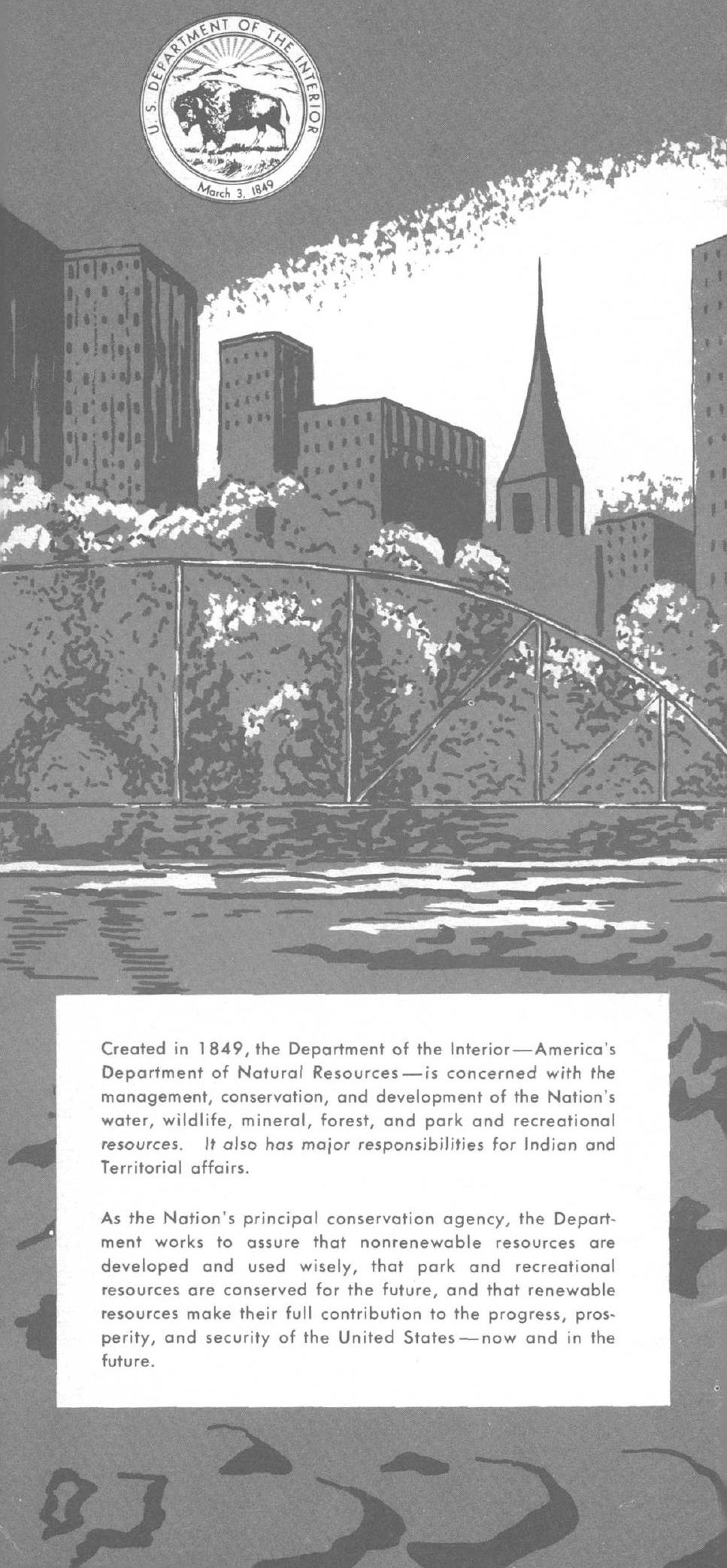

